\title{
A Review on Urinary Incontinence after Surgery for Benign Prostatic Hyperplasia
}

\author{
Constantin Martial Essissima Foé, Yunfen Liao, Guoxi Zhang \\ First Affiliated Hospital of Gannan Medical University, Ganzhou, China \\ Email: cessissimafoe@yahoo.fr, lyf130@126.com, gyfyurology@126.com
}

How to cite this paper: Foé, C.M.E., Liao, Y.F. and Zhang, G.X. (2022) A Review on Urinary Incontinence after Surgery for Benign Prostatic Hyperplasia. Open Journal of Urology, 12, 169-184.

https://doi.org/10.4236/oju.2022.123017

Received: February 1, 2022

Accepted: March 4, 2022

Published: March 7, 2022

Copyright ( 2022 by author(s) and Scientific Research Publishing Inc. This work is licensed under the Creative Commons Attribution International License (CC BY 4.0).

http://creativecommons.org/licenses/by/4.0/

\begin{abstract}
Background: Benign prostatic hyperplasia $(\mathrm{BPH})$ is characterized by the abnormal proliferation of cells, leading to structural changes. It is one of the most common diseases in ageing men. Its clinical presentations are dominated by lower urinary tract symptoms (LUTS). The therapeutic methods can be grouped into two options: the medical option and the surgical option in which prostate enucleation is found. In recent years many studies have reported the onset of urinary incontinence (UI) after prostate enucleation. The management of UI occurring after prostate enucleation is embarrassing for both the practitioner and the patient, and generates additional costs. Purpose: Cite the causes of UI after prostate enucleation for BPH, as well as ways to prevent the onset of UI after this surgery, specifically by the study of the vesicosphincteric system aimed at improving the technique of enucleation; our review will also deal with the therapeutic means of UI. Method: We retrieved studies from Science Direct, Wiley and Pubmed. Results: There are multiple etiologies of UI after prostate enucleation including urethral sphincter insufficiency (USI) and bladder dysfunction (BD). The management of UI after surgery could be conservative, surgical, or use new technologies. Urodynamic assessment before prostate enucleation for BPH is relevant. Conclusion: UI is a common post-operative complication of prostate enucleation. The study of the vesicosphincteric system leads us to believe that prostate enucleation for $\mathrm{BPH}$, partially sparing the mucosa and the external urethral sphincter could decrease the incidence of UI after surgery.
\end{abstract}

\section{Keywords}

Benign Prostatic Hyperplasia (BPH), Urinary Incontinence (UI), Urethral Sphincter Insufficiency (USI), Bladder Dysfunction (BD), Detrusor Overactivity (DO), Prostate Enucleation 


\section{Introduction}

Prostate adenoma or benign prostatic hyperplasia (BPH) is a new formation developed at the expense of prostate gland. Pathologically, BPH is characterized by the abnormal proliferation of cells (hyperplasia), leading to structural changes which can consist of stromal tissue, fibroblasts, smooth muscle cells and fibromuscular stroma or glandular tissue [1] [2]. The prevalence of BPH increases with age and it is one of the most common diseases in ageing men [3] [4]. Studies have observed histological prevalence of $9 \%, 50 \%$ and $80 \%$ in the $4^{\text {th }}, 6^{\text {th }}$ and $9^{\text {th }}$ decades of life, respectively [5]. Racial and ethnic variations are not evident in the incidence of BPH and symptoms severity [6]. It has been observed that lifestyle can modify the natural history of BPH [7] [8].

Its clinical presentations are dominated by lower urinary tract symptoms (LUTS) [9] [10] which can be classified in voiding symptoms (obstructive) and storage symptoms (irritative). International Prostate Symptoms Score (IPSS) and Quality of Life (QoL) index show objectively the severity of LUTS and the most bothersome symptoms. There are various therapeutic methods which can be grouped into two options: the medical option and the surgical option [11] [12], whereby, each option has several unique approaches. Over the past decades, surgical management, especially endoscopic, has continued to develop [13] [14] admitting effective surgical techniques which facilitate patient's short hospital stay and enhance rapid healing. It is important to note that the surgical treatment has well codified indications; surgical treatments are warranted when symptoms have not responded to conservative management, drug therapy, or when complications of BPH are diagnosed. The concerned complications are: obstructive renal insufficiency, recurrent acute retention despite medical treatment, acute retention of urine with failure of weaning of bladder drainage, recurrent macroscopic hematuria, recurrent urinary tract infections, bladder lithiasis or urinary incontinence by overflow.

However, in recent years many studies have reported complications related to surgical treatment, including urinary incontinence (UI) [15] [16]; several data reported that temporary UI occurs in more than $20 \%$ of patients after prostatic enucleation [17] [18]. UI is defined by the International Continence Society as a complaint of involuntary loss of urine [19]. Clinically, there are three main types of urinary incontinence: stress urinary incontinence (SUI), urinary incontinence due to urgency and mixed urinary incontinence [19].

UI is a common post-operative complication of prostate enucleation [17] [18], source of disappointment and psychological pressure for the attending physician and the concerned patient. However, publications revealed some predisposing factors in patients to urinary incontinence after enucleation for BPH including: advanced age, commorbidities (such as diabetes), a large size of the prostate gland, a long operating time, as well as significant blood loss during the operation. Several measures to prevent urinary incontinence after prostate enucleation have been reported: retaining the bladder neck, avoiding partial or complete 
damage to the external sphincter, avoiding radial strain of the sphincter, cutting the urethral mucosa at 12 points with sharp energy, and precise low-energy hemostasis. Although there are methods of preventing and treating urinary incontinence after prostatic enucleation for $\mathrm{BPH}$, the prevalence of post-surgical urinary incontinence remains high.

Anatomical and physiological study of the urethral sphincter reveals that the smooth muscle tissue located under the mucous membrane and near the external sphincter participates in urine control. We assume that the mucosa near the external sphincter has the effect of filling the gap left by the contraction of the sphincter. Based on the above two considerations, we believe that the mucosa near the external urethral sphincter plays an important role in urinary control; thus, we assume that prostatic enucleation for $\mathrm{BPH}$, partially sparing the mucosa and the external urethral sphincter could decrease the incidence of post-surgical UI. The reduction of urinary incontinence after surgery for BPH would undoubtedly be a source of satisfaction for the surgeon, the patient and an economic gain for society with regard to the diagnosis and management of this urinary incontinence.

\section{Anatomy of the Vesico-Sphincteric System in Men}

The bladder: The bladder is a hollow muscular organ whose function is to collect urine produced by the kidneys and stored at low pressure between urination. It is a stretchy and elastic organ.

External configuration: in adults, when it is empty, it is flattened and located entirely in the pelvic cavity applied to the posterior surface of the pubic symphysis and to the antero superior part of the pelvic floor [20] [21]. When it is distended, it is ovoid in shape and protudes in the abdomen. In men, it is in front of the seminal vesicles and rectum, and above the prostate (Figure 1).

Capacity: in adults, the maximum anatomical capicity is 2 to 3 liters. The physiological capacity is approximately $150 \mathrm{ml}$ for the first need to urinate and $300 \mathrm{ml}$ for the normal need.

Means of fixity and bladder compartment: the bladder is well maintained, with the exception of its upper surface by:

- Bladder fascia: it covers the infero-lateral surfaces and the fundus of the bladder;

- Umbilico-vesical ligament;

- Other ligaments: the median umbilical ligament, pubo-prostatic ligament in men, the lateral bladder ligaments, the sacrogenital ligaments;

- The pelvic diaphragm and perineum: they are the most important means of fixity; in men, the puboperinealis muscle and the perineum effectively support the prostate, which support the bladder.

Internal structure of the bladder: The bladder contains 3 orifices: 2 ureteral orifices approximately $2 \mathrm{~cm}$ apart from each other, and connected by the interureteric fold; 1 urethral orifice, forming with the 2 ureteral orifices, the bladder trigone. 
The wall of the bladder presents the same histological organization of that of the terminal third of the ureter, namely 3 tunics: a mucosa, a smooth muscle, an adventitious or serosa (Figure 2).

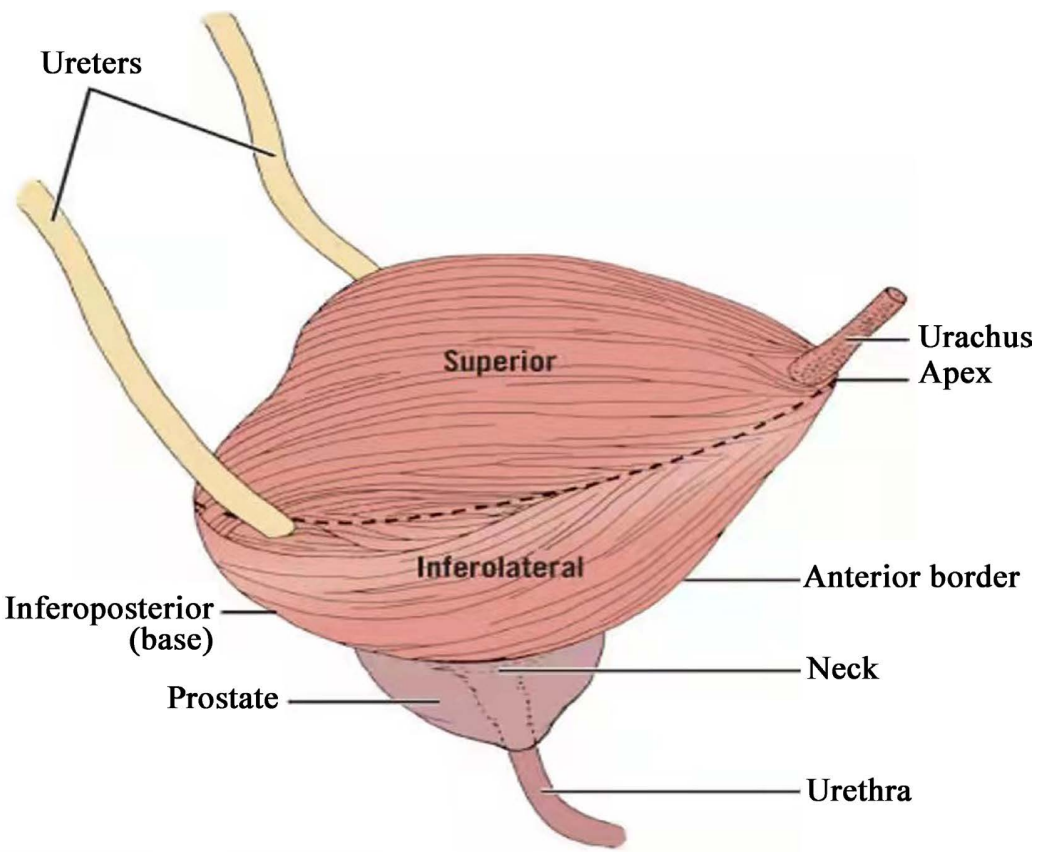

Ramesh, B. and Jnaneshwari, T.L. (2016) Textbook and Atlas of Laparoscopic Hysterectomy. 1/e, 27, 6 .

Figure 1. External configuration of the bladder.

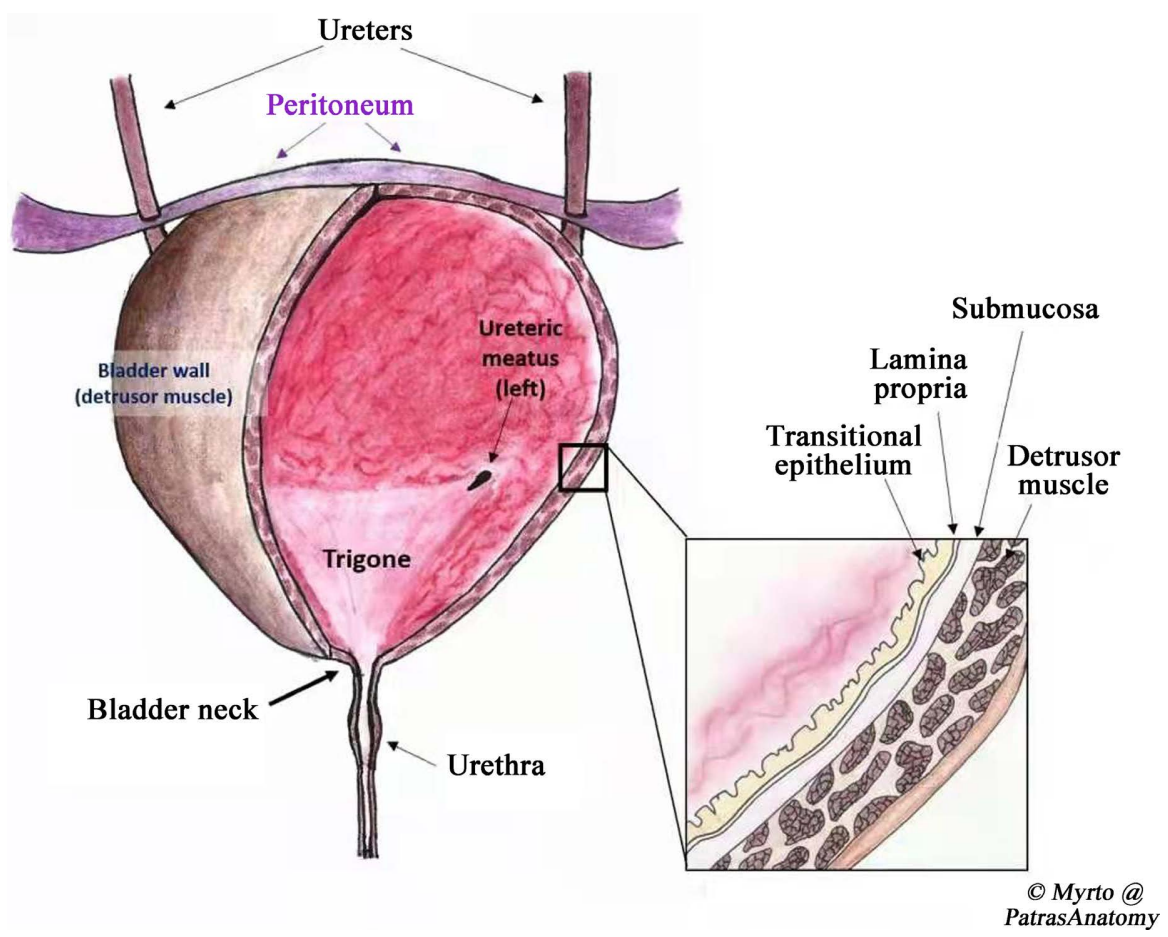

Jones, O. (2020) Teach me anatomy. The Urinary Bladder.

Figure 2. Internal configuration of the bladder. 
- The serosa: covers only the upper surface and partially the posterior and lateral surfaces;

- The muscularis or detrusor: formed of 3 concentric smooth muscle layers; a surface layer of longitudinal layers, a deep plexiform layer and the middle layer, the most important because it constitutes muscle thickening in the neck, the smooth sphincter of the bladder neck. This muscular structure is part of vesical sphincter that assures continous urinary continence, bladder neck closure during ejaculation and allow to avoid retrograde ejaculation;

- The mucous membrane: urothelium.

Male urethra: The urethra is a multi-layered fibro-muscular duct which allows urine to be excreted from the body. It starts from the bladder neck, descends through the prostate and the pelvic floor to enter the bulb of the penis. In men, the urethra is about $20 \mathrm{~cm}$ long and is divided into four parts: the prostatic urethra measuring approximately $4 \mathrm{~cm}$, the membranous urethra measuring approximately $3 \mathrm{~cm}$, the perineal urethra which follows the membranous urethra, the penile urethra which measures approximately $15 \mathrm{~cm}$ (Figure 3 ).

The urethral sphincter is found distal to the prostate tip. It is in close relationship with but independent of the pelvic floor musculature. The urethral sphincter consists of two muscle types [22] [23]:

- the outer striated muscle fibres extending to the apex and the anterior surface of the prostate;

- an inner muscle layer consists of smooth muscle fibres and elastic tissue. The smooth muscle layer has its proximal limits at the level of the verumontanum [24].

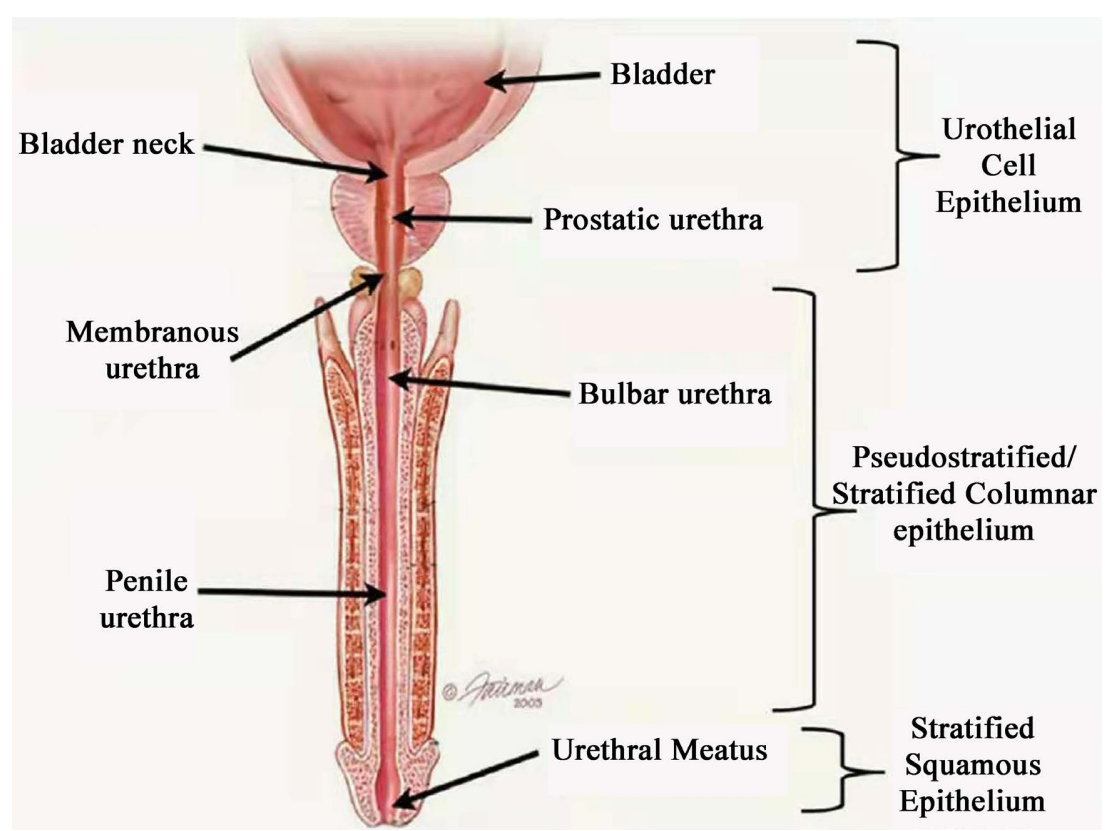

Furr, J., et al. (2020) Functional Anatomy of the Male Urethra for the Reconstructive Surgeon. Springer, Cham, 17-24.

Figure 3. Sagital view of the male urethra. 
The sphincter system: There are two well identified urinary sphincter systems: a proximal internal urethral sphincter assimilited to the vesical sphincter and the distal urethral sphincter assimilated to the external urethral sphincter [25].

The internal sphincter is made up of two layers: a longitudinal layer which intervenes during urination by opening cervix and shortening the urethra. It starts at the bladder neck and prolongs the smooth muscle of the trigone to join the verumontanum; a thicker circular layer at the level of the bladder neck in men, to form the preprostatic sphincter. Classically, these fibers behave like an authentic sphincter, that is to say an independent structure having its own innervation, capable of contracting and relaxing to ensure closure or opening of the cervix and the urethra [26].

The external sphincter consists of two parts: peri-urethral sphincter which is a part of the pelvic floor and is separated from the wall of the urethra by a plane of connective tissue: this is called the "external sphincter" classically described in books, located below the tip of the prostate; the para-urethral sphincter made up of the entire striated musculature from the bladder neck to the middle fascia of the perineum and is intimately associated with the urethral musculature and forms a sleeve externally lining the smooth sphincter [27].

Vasculature of the vesico-sphincteric system: The vesical vasculature is provided by branches of the internal iliac artery (Figure 4):

- A latero-superior sphincter pedicle to the lateral part of the bladder;

- A posterior pedicle formed by vesical branches of the inferior bladder artery;

- An antero-inferior pedicle deriving from a branch of the internal pudental artery.

The spongy urethra is supplied by the dorsal arteries of the penis, collateral to the internal pudental artery.

The vasculature of the striated sphincter is also provided by the pudental arteries.

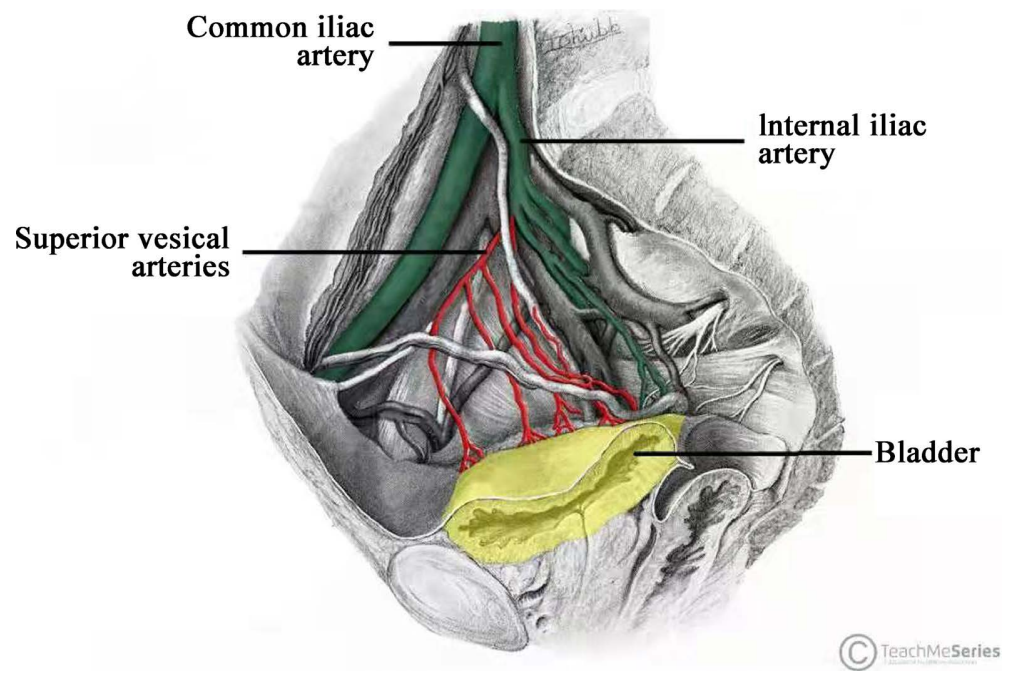

Jones, O. (2020) Teach me anatomy. The Urinary Bladder.

Figure 4. Arterial supply to bladder. 
The global venous return takes place in the venous plexus of santorini, and from there, in the internal pudental veins [28] [29].

Lymphatic drainage passes through the para-vesical nodes, then the internal iliac nodes and those of the promontory.

Innervation of the vesico-sphincteric system: The innervation of the vesico-sphincteric system is complex [30].

The coexistence within the lower urinary tract of a smooth musculature and a striated musculature requires a double innervation: vegetative and somatic.

- Vegetative innervation includes: hypogastric nerves, sympathetic fibers, pre and post-ganglion sympathetic neurons; parasympathetic afferents are formed by the pelvic nerves.

Somatic innervation is ensured by the branches of the pudental plexus, formed by the union of S2, S3 and S4, giving the nerves of the elevator of the anus (S3 and S4), the nerves of the sacrococcygeal muscle (S4) and the pudental nerve. Their medullary centers are located in the ventral horn of the $2^{\text {nd }}, 3^{\text {rd }}$ and $4^{\text {th }}$ sacral segments.

\section{Physiology of Continence and Male Micturition}

The bladder must be able both to hold urine without weakness and to expel urine effortlessly.

The vesico-sphincteric function is subjected to a neurological control developed at 2 levels: automatic control, reflex, which regulates the alternation of filling and urination; brain control, voluntary, which makes it possible to order or refuse voiding reflex [31].

The filling phase: When filling, the bladder spreads out loosely in the small pelvis, its base becoming horizontal, and its neck remaining closed even during heavy coughing efforts. Continence is ensured by a simple gradient largely positive urethrovesical pressure.

Holding forces consist of 2 components:

- Urethral pressure: the maximum value is around 60 to $80 \mathrm{~cm}$ of water, increases during bladder filling, and collapses during urination [32];

- Urethral resistance, which is greater in men than women which is explained by the greater urethral length on the one hand, and by the presence of denser peri-urethral tissues such as the prostate on the second hand.

The filling phase is under the control of the sympathetic system, resulting in the relaxation of the detrusor (alpha receptors) and especially tonic contraction of the smooth muscle fibers of the cervix and urethra (beta receptors).

Urinary continence at rest: The bladder pressure for filling remains low, not exceeding $15 \mathrm{~cm}$ of water for a volume of $300 \mathrm{ml}$. This ability to store a large volume at low pressure is called 'compliance', thus helping to protect the upper urinary tract, and is explained by the elastic properties of the bladder [32].

Stress urinary continence: Some efforts, such as coughing, laughing, walking, or switching to orthostatism, raise the abdominal and intravesical pressure 
up to $100 \mathrm{~cm}$ of water and more, which may overwhelm the restraining forces described above. However, there is a synchronous increase in urethral pressure to ensure continence. This phenomenon is explained by a somatic reflex called continence ("guarding reflex") resulting in the contraction of the perineo-sphincteric musculature [32].

The voiding phase: During urination, the bladder contracts concentrically. Its base turns into a funnel and its cervix opens with the urethra, allowing urine to pass. Bladder pressure rises between 30 and $60 \mathrm{~cm}$ of water, when urethral pressure collapses [32].

The voiding reflex: It corresponds to the intervention of the parasympathetic system, with 2 main effects:

- Powerfull and organized contraction, qualified as 'phasic', of all the detrusor smooth muscle cells;

- Collapse of the sphincter tone by reflex inhibition of the antagonistic system, sympathetic and somatic. This reflex coordination of the parasympathetic activation, coupled with the inhibition of the sympathetic and the somatic is organized at 2 levels: at the medullary centers and in the peripheral ganglion plexuses for sympathetic/parasympathetic coordination, at the brainstem centers for parasympathetic/somatic coordination.

Brain control of the voiding reflex: The need to urinate arises from stimulation of the detrusor tension receptors, carrying informations to the parietal cortex via the extralemniscal route.

Brain control is used to trigger or inhibit the voiding reflex organized in the centers of braintem, thanks to the connexion linking them to the cortical and subcortical centers. This is how reflex urination can be triggered [31].

These anatomical and physiological studies of the vesico-sphincteric system suggest that prostatic enucleation for $\mathrm{BPH}$, partially sparing the urethral mucosa at the level of external sphincter, could reduce the incidence of UI occuring after surgery.

\section{The Different Types of UI}

There are five types of UI: stress UI (SUI), UI due to urgency, mixed UI (MUI), overflow and functional urinary incontinence [33].

In our review, we will talk about the three main types of UI: SUI, UI due to urgency and MUI.

SUI: Efforts such as coughing, giggling, walking can increase intra-abdominal pressure and lead to urinary incontinence. This form of incontinence is characterized by weakness of the muscles of the perineum and the urinary sphincter [34].

UI due to urgency: It is characterized by an involuntary leakage of urine through the urethral canal, accompanied or immediately preceded by an urgent and irrepressible need to urinate, resulting in urination which cannot be postponed and retained. This type of incontinence fits into the "overactive bladder syndrome" which is characterized by the onset of a sudden and difficult urge to 
urinate, even impossible to control, defined by the term "urgency" [34].

MUI: It associates SUI with urinary urge incontinence.

\section{Pathophysiology}

The onset of LUTS after BPH enucleation is heterogeneous and has multiple origins, and may be the result of hypoxic rearrangement, neuromuscular changes, from chronic outlet obstruction. The distension of the bladder from bladder outlet obstruction (BOO) may cause muscle and epithelial modifications of gene expression and protein synthesis; this process alters the physiology and cellular structure of cell. The result is smooth muscle hyperplasia and bladder wall thickening with poor contractility, small capacity, and low compliance. Also, we think that BOO increases nerve growth factor, driving a neurotrophic effect on bladder neurons to help overcome outlet resistance during micturition. However, these hyperactive neuronal pathways may persist and be the source of irritative storage symptoms and detrusor overactivity. Also, vascular compression from chronic bladder distension may reduce perfusion to the bladder wall and cause neuronal death and severe denervation. This situation could lead to detrusor underactivity [35].

If they are entirely caused by the $\mathrm{BOO}, \mathrm{OAB}$ symptoms should disappear following relief of obstruction; if, however, they are not, then they may persist following surgery. Thus, correct pre-operative characterization of LUTS is important before offering prostate enucleation for BPH [12].

This is how many studies have demonstrated the importance of UDS assessments in patients before surgery for $\mathrm{BPH}$, or with persistent LUTS following BOO surgery [36] [37].

\section{Diagnosis}

\section{Clinical diagnosis:}

- Anamnesis: it focuses on the age of the patient, the medical and surgical history. A voiding calendar: the frequency (with schedule) and the volume of urination as well as the volume of drinks are carefully recorded in parallel with the frequency and importance of incontinence episodes as well as the quantity of pads used give both patient and physician a clear and objective table of incontinence.

- Voiding calendar: also useful to monitor the effect of the treatment instituted. It must be established over at least three consecutive days.

- Symptoms (Table 1) and quality of life scores (Table 2): they make it possible to assess the severity of incontinence, as well as its impact on the patient's daily life. Subsequently, will be used to evaluate the effectiveness of the choosen treatment.

- Physical examination: it includes an abdominal and rectal status as well as a summary neurological status; the examination of the external genitalia is of course essential. 
Table 1. International Prostatic Symptoms Score (IPSS).

\begin{tabular}{|c|c|c|c|c|c|c|}
\hline Over the past month & $\begin{array}{l}\text { Not } \\
\text { at all }\end{array}$ & $\begin{array}{l}\text { Less than } \\
\text { one time } \\
\text { in five }\end{array}$ & $\begin{array}{l}\text { Less than } \\
\text { half the } \\
\text { time }\end{array}$ & $\begin{array}{l}\text { About } \\
\text { half } \\
\text { the time }\end{array}$ & $\begin{array}{l}\text { More than } \\
\text { half the } \\
\text { time }\end{array}$ & $\begin{array}{l}\text { Almost } \\
\text { always }\end{array}$ \\
\hline $\begin{array}{l}\text { Incomplete emptying; How often have you had the sensation of not } \\
\text { emptying your bladder completely after you finished urinating? }\end{array}$ & 0 & 1 & 2 & 3 & 4 & 5 \\
\hline $\begin{array}{l}\text { Frequency; How often have you had to urinate again less than two } \\
\text { hours after you finished urinating? }\end{array}$ & 0 & 1 & 2 & 3 & 4 & 5 \\
\hline $\begin{array}{l}\text { Intermittency; How often How often you have found you stopped } \\
\text { and started again several times when you urinate? }\end{array}$ & 0 & 1 & 2 & 3 & 4 & 5 \\
\hline $\begin{array}{l}\text { Urgency; How often have you found it difficult to postpone } \\
\text { urination? }\end{array}$ & 0 & 1 & 2 & 3 & 4 & 5 \\
\hline $\begin{array}{l}\text { Weak stream; How often have had to push or strain to begin } \\
\text { urination? }\end{array}$ & 0 & 1 & 2 & 3 & 4 & 5 \\
\hline $\begin{array}{l}\text { Sleeping; How many times did you most typically get up to urinate } \\
\text { from the time you went to bed a t night until the time you got up } \\
\text { in the morning? }\end{array}$ & 0 & 1 & 2 & 3 & 4 & 5 \\
\hline Symptoms scores & & & & & & \\
\hline
\end{tabular}

Total International Prostate Symptoms Score: 1 - 7 mild symptoms; 8 - 19 moderate symptoms; 20 - 35 severe symptoms.

Table 2. Quality of life index.

\begin{tabular}{|c|c|c|c|c|c|}
\hline Quality of life (Qol) & Delighted Pleased & $\begin{array}{l}\text { Mostly } \\
\text { satisfied }\end{array}$ & Mixed & $\begin{array}{c}\text { Mostly } \\
\text { dissatisfied }\end{array}$ & Unhappy Terrible \\
\hline $\begin{array}{c}\text { If you were to spend the rest of your life with your urinary } \\
\text { condition just the way it is now, how would you feel about } \\
\text { that? }\end{array}$ & 0 & 2 & 3 & 4 & 6 \\
\hline
\end{tabular}

\section{Paraclinical diagnosis:}

- Biology: uroanalysis gives informations of possible micro-haematuria, glucosuria or leukocyturia, bacterial culture, PSA dosage.

- Imaging: by transabdominal ultrasound, the post-voiding residue can be assessed; CT and MRI are special in this indication.

- Endoscopy: performing a urethrocystoscopy is necessary to verify the absence of urethral stenosis, urethral bridle, or bladder abnormality that may explain the lack of bladder compliance. Finally, urethrocystoscopy allow us to assess urethral fibrosis, a bladder neck sclerosis and urethral tenderness.

- Urodynamic diagnosis: it must be performed before any surgical treatment in order to specify the mechanism of urinary incontinence; it includes at least a flowmetry with measurement of the post-voiding residue, urethral profilometry with measurement of the maximum closing pressure of the urethra, cystomanometry with measurements of the bladder capacity and sensitivity and a measurement of the "leak point pressure" (intravesical or abdominal pressure associated with a urine leak) assessing the functional value of the 
sphincter system.

\section{Etiologies}

There are multiple etiologies of UI after surgery for $\mathrm{BPH}$, including: urethral sphincter insufficiency (USI) and/or bladder dysfunction (BD). BD can be a decreased compliance (DC) or detrusor overactivity (DO) [38] [39]. Some data have reported that more than $60 \%$ of UI were due to $\mathrm{BD}$, probably as a result of a chronic obstruction caused by BPH [40].

Older patients have greater rates of $\mathrm{BD}$ and patients older than 70 years of age may be considered a high risk group [38] [39].

\section{Management}

\section{Conservative management}

- Behavioral, lifestyle modification (weight loss if necessary, decrease in consumption of caffeine and tobacco, regular physical activity, changes in fluid intake) or reevaluation can be used as the first line of treatment.

- Re-education: there are many physiotherapy techniques (pelvic floor muscle training, electrostimulation) and it is recommended to combine several in order to obtain maximum efficiency.

- Drugs: the choice of the drug introduced must be adapted to the physiopathological mechanism involved in the patient's UI. In case of stress incontinence, we can use duloxetine; in case of overactive bladder, we can use oxybutinin, trospium hydrochlorid, flavoxate, tolterodine and solifenacin.

If obstruction is suspected, it would be prudent to determine whether urethral or meatal stricture or bladder neck contracture, as these parts may require endoscopic resection or incision, dilation or complex re-construction.

\section{Surgical management}

- Peri or intra-urethral injections: the goal of intra injections of fillers is to create resistance to the flow of urine by increasing urethral coaptation. Several products were used: bovine collagen, silicone, carbon ziconium, hyaluronic acid, autologous fat, macroplastic, polydimethylsiloxane and non-silicone polyvinylpyrrolidone [41].

- Peri-urethral balloons: this is a system of two silicone balloons implanted on either side of the urethra by the perineal route, connected by a tube to an injection port or chamber allowing to fill or empty the balloon. They aim to compress the urethra in the region of the deficient striated external sphincter.

- The artificial sphincter: this is the standard treatment for UI for sphincter insufficiency. Its implantation technique has been standardized but remains complex and not without risk [41].

- External urinary diversion.

Sub-urethral strips: Sub-urethral strips appear as protheses at lower risk than artificial sphincter and at lower cost. The principle is to increase, by compression and therefore decrease in the diameter of the residual urethra, the number of sphincter cells available to ensure continence [42]. 
Neuromodulation: Sacral neuromodulation (SNM) involves the placement of an electrode into the third sacral (S3) foramen which is connected to a generator and battery, electrically stimulating the nerve root and suppressing the reflexes responsible for involuntary detrusor contractions. Currently, it is recommended in those who have failed or cannot tolerate conservative and medical treatment [42].

\section{Discussion}

Studies agree that the diagnosis of UI occurring after enucleation of the prostate for BPH is simple [9] [10]. Publications on the factors predisposing to the occurrence of UI after surgery seem to draw similar conclusions: advanced age, commorbidities such as diabetes, a large size of the prostate gland, a long operating time, as well as significant blood loss during the operation [15] [16] [36] [38].

The etiologies are multiples and similar in many publications [28] [39] [40]. However, these etiologies are dominated by BD [40], probably as a result of a chronic obstruction caused by BPH. Several means of prevention have been published: retaining the bladder neck, avoiding partial or complete damage to the external sphincter, cutting the urethral mucosa at 12 points with sharp energy, and precise low-energy hemostasis. Despite all these measures, the prevalence of UI occurring after prostate surgery for $\mathrm{BPH}$ remains high.

The study of the vesico-sphinteric system [20] [21] [22] [31] [32] [33], notably of the external urethral sphincter reveals that the mucosa near the external sphincter has the effect of filling the gap left by the contraction of the sphincter. Based on the above two considerations, we believe that the mucosa near the external urethral sphincter plays an important role in urinary control; thus, we assume that prostatic enucleation for $\mathrm{BPH}$, partially sparing the mucosa and the external urethral sphincter could decrease the incidence of post-surgical urinary incontinence. This new surgical approach could help to reduce the incidence of UI occurring after prostate surgery.

This new approach is the subject of much scientific interests in many hospital centers in China, notably at the First Affiliated Hospital of Gannan Medical University where the prostate enucleation technique is well mastered. The technique of prostate enucleation is not yet widespread in many countries of sub-saharan Africa and should be the subject of interests over the next decade.

\section{Conclusion}

Urinary incontinence is a common post-operative complication of prostate enucleation; its diagnosis is simple. Risk factors are known: advanced age, commorbidities such as diabetes, a large size of the prostate gland, a long operating time, as well as significant blood loss during the operation. Despite the publication of many methods to avoid the occurrence of UI after prostatic enucleation, the prevalence remains high. After a study of the vesico-sphincteric system, we 
assume that prostatic enucleation for $\mathrm{BPH}$, partially sparing the mucosa and the external urethral sphincter could decrease the incidence of post-surgical urinary incontinence. This hypothesis could be the subject of many studies.

\section{Conflicts of Interest}

The authors declare no conflicts of interest regarding the publication of this paper.

\section{References}

[1] Oelke, M., Höfner, K., Udo, J., Karl-Ulrich, L. and Ulf, T. (2007) Benign Prostatic Hyperplasia: Terminology and Assessment. Deutsches Arzteblatt, 104, 2261-2267. https://www.aerzteblatt.de/int/article.asp?id=56652

[2] Ashfaq U.H. and Rasool Z. (2013) A Histological Study of Prostate. International Journal of Research in Medical Sciences, 1, 557-562. https://doi.org/10.5455/2320-6012.ijrms20131144

[3] Lokeshwar, S.D., Harper, B.T., Webb, E., Jordan, A., Dykes, T.A., Neal Jr., D.E., et al. (2019) Epidemiology and Treatment Modalities for the Management of Benign Prostatic Hyperplasia. Translational Andrology and Urology, 8, 529-539. https://doi.org/10.21037/tau.2019.10.01

[4] Lim, K.B. (2017) Epidemiology of Clinical Benign Prostatic Hyperplasia. Asian Journal of Urology, 4, 148-151. https://doi.org/10.1016/j.ajur.2017.06.004

[5] Berry, S.J., Coffey, D.S., Walsh, P.C. and Ewing, L.L. (1984) The Development of Human Benign Prostatic Hyperplasia with Age. Journal of Urology, 132, 474-479. https://doi.org/10.1016/S0022-5347(17)49698-4

[6] Platz, E.A., Kawach, I., Rimm, E.B., Willett, W.C. and Giovannucci, E. (2000) Race, Ethnicity and Benign Prostate Hyperplasia in the Health Professional Follow-up Study. Journal of Urology, 163, 490-495. https://doi.org/10.1016/S0022-5347(05)67909-8

[7] Parsons, J.K. (2007) Modifiable Risk Factors for Benign Prostatic Hyperplasia and Lower Urinary Tract Symptoms: New Approaches to Old Problems. Journal of Urology, 178, 395-401. https://doi.org/10.1016/j.juro.2007.03.103

[8] Kristal, A.R, Arnold, K.B., Schenk, J.M., Neuhouser, M.L., Goodman, P., Penson, D.F., et al. (2008) Dietary Patterns, Supplement Use, and the Risk of Symptomatic Benign Prostatic Hyperplasia: Results from the Prostate Cancer Prevention Trial. American Journal of Epidemiology, 167, 925-934. https://doi.org/10.1093/aje/kwm389

[9] Vasanwala, F., Wong, M.C., Ho, H.S. and Foo, K.T. (2017) Benign Prostatic Hyperplasia and Male Lower Urinary Symptoms: A Guide for Family Physicians. Asian Journal of Urology, 4, 181-184. https://doi.org/10.1016/j.ajur.2017.05.003

[10] Zhang, W., Zhang, H., Li, H., Wu, F., Wang, H., Zhao, M., et al. (2019) Prevalence of Lower Urinary Tract Symptoms Suggestive of Benign Prostatic Hyperplasia (LUTS/BPH) in China: Results from the China Health and Retirement Longitudinal Study. BMJ Open, 9, e022792. https://doi.org/10.1136/bmjopen-2018-022792

[11] Gravas, S., Cornu, J.N., Gacci, M., Gratzke, C., Herrmann, T.R.W., Mamoulakis, C., et al. (2020) EAU Guidelines on Management of Non-Neurogenic Male Lower Urinary Tract Symptoms (LUTS), incl. Benign Prostatic Obstruction (BPO). European Association of Urology, 94, 15-46.

http://uroweb.org/guidelines/compilations-of-all-guidelines 
[12] Macey, M.R. and Raynor, M.C. (2016) Medical and Surgical Treatment Modalities for Lower Urinary Tract Symptoms in the Male Patient Secondary to Benign Prostatic Hyperplasia: A Review. Seminar of Interventional Radiology, 33, 217-223. https://doi.org/10.1055/s-0036-1586142

[13] Huang, S.W., Tsai, C.Y., Tseng, C.S., Shih, M.C., Yeh, Y.C., Chien, K.L., et al. (2019) Comparative Efficacy and Safety of New Surgical Treatments for Benign Prostatic Hyperplasia: Systematic Review and Network Meta-Analysis. British Medical Journal, 367, Article No. 15919. https://doi.org/10.1136/bmj.15919

[14] Carmignani, L., Clementi, M.C., Signorini, C., Motta, G., Nazzani, S., Palmisano, F., et al. (2019) Safety and Feasibility of Thulium Laser Transurethral Resection of Prostate for the Treatment of Benign Prostatic Enlargement in Overweight Patients. Asian Journal of Urology, 6, 270-274. https://doi.org/10.1016/j.ajur.2018.05.004

[15] Song, W., Wu, J., Gai, J., et al. (2018) Holmium Laser Enucleation of the Prostate Prevents Postoperative Stress Incontinence in Patients with Benign Prostate Hyperplasia. International Journal of Clinical and Experimental Medicine, 11, 2572-2576.

[16] Nam, J.K., Kim, H.W., Lee, D.H., Han, J.Y., Lee, J.Z. and Park, S.W. (2015) Risk Factors for Transient Urinary Incontinence after Holmium Laser Enucleation of the Prostate. The World Journal of Men's Health, 33, 88-94.

https://doi.org/10.5534/wjmh.2015.33.2.88

[17] Anan, G., Kaih, Y., Iwamura, H., Ito, J., Kohada, Y., Mikami, J., et al. (2020) Preoperative Pelvic Floor Muscle Exercise for Early Continence after Holmium Laser Enucleation of the Prostate: A Randomized Controlled Study. BMC Urology, 20, Article No. 3. https://doi.org/10.1186/s12894-019-0570-5

[18] Sapetti, J., Sakat, J., Saad, E., Zerbib, M., Belas, O., Doru-Pop, C., et al. (2019) Urinary Incontinence after HOLEP: Incidence, Evolution and Predictive Factors. Progrès en Urology, 29, 101-107. https://doi.org/10.1016/j.purol.2018.12.008

[19] International Continence Society (2019) The 2019 Compilation of the International Continence Society Standardisations Consensus Statements, Educational Modules, Terminology and Fundamental Documents, with the International Consultations on Incontinence Algorithms. International Continence Society, Bristol. Neurourology and Urodynamics, 29, 4-20.

[20] Partin, A.W., Peters, C.A., Dmochowsky, R.R., Kavoussi, L.R. and Wein, A.J. (2020) Campbell Walsh Wein Urology. 12th Edition, Elservier, Amsterdam.

[21] Shermadou, E.S., Rahman, S. and Leslie, S.W. (2021) Anatomy, Abdomen and Pelvis, Bladder. [Updated 2021 July 31]. In: StatPearls, StatPearls Publishing, Treasure Island. https://www.ncbi.nlm.nih.gov/books/NBK531465

[22] Strasser, H. and Bartsch, G. (2000) Anatomy and Innervation of the Rhabdosphincter of the Male Urethra. Seminar in Urologic Oncology, 18, 2-8.

[23] Rocco, F., Carmignani, L., Acquati, P., Gadda, F., Dell'Orto, P., Rocco, B., et al. (2007) Early Continence Recovery after Open Radical Prostatectomy with Restoration of the Posterior Aspect of the Rhabdosphincter. European Urology, 52, 376-383. https://doi.org/10.1016/j.eururo.2007.01.109

[24] Ganzer, R., Blana, A., Gaumann, A., Stolzenburg, J.U., Rabenalt, R., Bach, T., et al. (2008) Topographical Anatomy of Periprostatic and Capsular Nerves: Quantification and Computerised Planimetry. European Urology, 54, 353-361. https://doi.org/10.1016/j.eururo.2008.04.018

[25] Walz, J., Epstein, J.I., Ganz, R., Graefen, M., Guazzoni, G., Kaouk, J., et al. (2006) A Critical Analysis of the Current Knowledge of Surgical Anatomy of the Prostate Related to Optimisation of Cancer Control and Preservation of Continence and Erec- 
tion in Candidates for Radical Prostatectomy: An Update. European Urology, 70, 301-311. https://doi.org/10.1016/j.eururo.2016.01.026

[26] McGuire, E.J., Woodside, J.R., Borden, T.A. and Weiss, R.M. (1981) Prognostic Value of Urodynamic Testing in Myelodysplastic Patients. Journal of Urology, 126, 205-209. https://doi.org/10.1016/S0022-5347(17)54449-3

[27] Dorschner, W., Biesold, M., Schmidt, F. and Stolzenburg, J.U. (2009) The Dispute about the External Sphincter and the Urogenital Diaphragm. Journal of Urology, 162, 1942-1945. https://doi.org/10.1016/S0022-5347(05)68074-3

[28] Sam, P., Nassereddin, A. and LaGrange, C.A. (2020) Anatomy, Abdomen and Pelvis, Bladder Detrusor Muscle. StatPearls, Treasure Island.

[29] Matin, S.F. (2006) Recognition and Preservation of Accessory Pudendal Arteries during Laparoscopic Radical Prostatectomy. Urology, 67, 1012-1015. https://doi.org/10.1016/j.urology.2005.11.010

[30] De Groat, W.C., Griffiths, D. and Yoshimura, N. (2015) Neural Control of the Lower Urinary Tract. Comprehensive Physiology, 5, 327-396.

https://doi.org/10.1002/cphy.c130056

[31] Cortes, G.A. and Flores, J.L. (2021) Physiology, Urination [Updated 2021 July 26]. In: StatPearls, StatPearls Publishing, Treasure Island. https://www.ncbi.nlm.nih.gov/books/NBK562181/.

[32] Yao, M. and Simoes, A. (2021) Urodynamic Testing and Interpretation [Updated 2021 August 11]. In: StatPearls, StatPearls Publishing, Treasure Island. https://www.ncbi.nlm.nih.gov/books/NBK562310

[33] Abrams, P., Cardozo, L., Fall M., Griffiths, D., Rosier, P., Ulmsten, U., et al. (2002) The Standardisation of Terminology of Lower Urinary Tract Function: Report from the Standardisation Sub-Committee of the International Continence Society. American Journal of Obstetrics and Gynecology, 187, 116-126.

https://doi.org/10.1067/mob.2002.125704

[34] Mangir, N. and Chapple, C. (2020) Management of Urinary Incontinence in Men. Trends Urology \& Men's Health, 11, 18-22. https://doi.org/10.1002/tre.740

[35] Singla, N. and Singla, A.K. (2016) Evaluation and Management of Lower Urinary Tract Symptoms after Outlet Surgery for Benign Prostatic Hyperplasia. Current Bladder Dysfunction Report, 11, 242-247. https://doi.org/10.1007/s11884-016-0376-1

[36] Han, H.H., Ko, W.J., Yoo, T.K., Oh, T.H., Kim, D.Y., Kwon, D.D., et al. (2014) Factors Associated with Continuing Medical Therapy after Transurethral Resection of Prostate. Urology, 84, 675-680. https://doi.org/10.1016/j.urology.2014.04.027

[37] Seaman, E.K., Jacobs, B.Z., Blaivas J.G. and Kaplan, S.A. (1994) Persistence or Recurrence of Symptoms after Transurethral Resection of the Prostate: A Urodynamic Assessment. Journal of Urology, 152, 935-937. https://doi.org/10.1016/S0022-5347(17)32614-9

[38] Bruschini, H., Simonetti, R., Antunes, A.A. and Srougi, M. (2011) Urinary Incontinence Following Surgery for BPH: the Role of Aging on the Incidence of Bladder Dysfunction. International Brazilian Journal of Urology, 37, 380-387. https://doi.org/10.1590/S1677-55382011000300012

[39] Ficazzola, M.A. and Nitti, V.W. (1998) The Etiology of Post-Radical Prostatectomy Incontinence and Correlation of Symptoms with Urodynamic Findings. Journal of Urology, 160, 1317-1320. https://doi.org/10.1016/S0022-5347(01)62525-4

[40] Goluboff, E.T., Chang, D.T., Olsson, C.A. and Kaplan, S.A. (1995) Urodynamics and the Etiology of Post-Prostatectomy Urinary Incontinence: The Initial Columbia 
Experience. Journal of Urology, 153, 1034-1037.

https://doi.org/10.1016/S0022-5347(01)67629-8

[41] Downey, A. and Inman, R.D. (2019) Recent Advances in Surgical Management of Urinary Incontinence. F1000Research, 8, Article No. 1294.

https://doi.org/10.12688/f1000research.16356.1

[42] Kretschmer, A., and Gratzke, C. (2018) Therapeutic Options for Stress Urinary Incontinence Following Surgery for Benign Prostate Enlargement. Aktuelle Urologie, 49, 334-338. https://doi.org/10.1055/a-0642-1701

\section{Abbreviations}

BD: bladder Dysfunction

BOO: Bladder Outlet Obstruction

BPH: Benign Prostatic Hyperplasia

DC: Decrease Compliance

DO: Detrusor Overactivity

IPSS: International Prostate Score Symptoms

LUTS: Lower Urinary Tract Symptoms

MUI: Mixed Urinary Incontinence

QoL: Quality of Life

SUI: Stress Urinary Incontinence

UI: Urinary Incontinence

USI: Urethral Sphincter Insufficiency 